\title{
Cancer Patients With Major Depressive Disorder: Testing a Biobehavioral/Cognitive Behavior Intervention
}

\author{
Brittany M. Brothers, Hae-Chung Yang, Daniel R. Strunk, and Barbara L. Andersen \\ The Ohio State University
}

\begin{abstract}
Objective: In this Phase II trial, we evaluated a novel psychological treatment for depressed patients coping with the stresses of cancer. Effectiveness of a combined biobehavioral intervention (BBI) and cognitive behavior therapy (CBT) was studied. Method: Participants were 36 cancer survivors (mean age $=49$ years; $88 \%$ Caucasian; $92 \%$ female) diagnosed with major depressive disorder. A single group pre-post design was used. Treatment consisted of up to 20 individual 75-min combined BBI/CBT sessions. Outcomes were change in interviewer (Hamilton Rating Scale for Depression; Williams, 1988) and self-rated depressive symptoms (Beck Depression Inventory-Second Edition; Beck, Steer, \& Brown, 1996) as well as change in cancer relevant symptoms (Fatigue Symptom Inventory [Hann et al., 1998] and Brief Pain Questionnaire [Daut, Cleeland, \& Flanery, 1983]) and quality of life (Medical Outcomes Study Short Form-36; Ware et al., 1995). Mixed-effects modeling, a reliability change index, and generalized linear models were used. All analyses were intent-to-treat. Results: Depressive symptoms significantly improved. In addition, 19 of 21 study completers met criteria for remission. Significant improvements were also noted in fatigue and mental health quality of life. Both concurrent anxiety disorders and high levels of cancer stress (Impact of Events Scale; Horowitz, Wilner, \& Alvarez, 1979) were each associated with beginning and concluding treatment with greater depressive symptoms. Conclusions: CBT components were successfully incorporated into a previously efficacious intervention for reducing cancer stress. The BBI/CBT intervention warrants further research in evaluating its efficacy compared with well-established treatments for depression.
\end{abstract}

Keywords: depression, cancer, survivors, cognitive behavior therapy, biobehavioral intervention

Estimates for major depressive disorder (MDD) are 22\%-29\% for newly diagnosed cancer patients (Raison \& Miller, 2003). Predictors of depression include cancer-specific traumatic stress (Palmer, Kagee, Coyne, \& DeMichele, 2004), prior depressive episodes, and presence of comorbid anxiety disorders (e.g., Burgess et al., 2005). Depressive symptoms predict poorer quality of life (QoL; Golden-Kreutz \& Andersen, 2004) and greater fatigue (e.g., Smith, Gomm, \& Dickens, 2003) but are frequently undetected or underestimated by oncologists and nurses (McDonald et al., 1999). Unfortunately, there is no intervention designed specifically for cancer patients with MDD. Two recent trials $(\mathrm{Ns} \leq 45)$ have adapted cognitive behavior therapy (CBT) to the context of cancer (Hopko et al., 2008; Savard et al., 2006) and have significantly reduced depressive symptoms. Other trials typically exclude clinically depressed patients, and those with MDD patients often had only modest benefit, if any (e.g., Weber et al.,

This article was published Online First February 21, 2011

Brittany M. Brothers, Comprehensive Cancer Center, The Ohio State University; Hae-Chung Yang, Daniel R. Strunk, and Barbara L. Andersen, Department of Psychology, The Ohio State University.

Funding provided by the Columbus Affiliate of Susan G. Komen for the Cure, The Ohio State University Targeted Investments in Excellence Award, The Ohio State University Graduate School, and the National Cancer Institute (Grant 2K05CA098133).

Correspondence concerning this article should be addressed to Brittany M. Brothers, Comprehensive Cancer Center, The Ohio State University, 159 Psychology Building, 1835 Neil Avenue, Columbus, OH 43210. E-mail: brittany.brothers@osumc.edu
2004). Lastly, psychosocial interventions for cancer patients have been found to be more effective in treating symptoms of anxiety rather than depression (i.e., Sheard \& Maguire, 1999).

In light of this problem, our aim was to design an intervention that would address the unique needs and challenges facing cancer patients with comorbid depression. The Biobehavioral Model of Cancer Stress and Disease Course (Andersen, Kiecolt-Glaser, \& Glaser, 1994) postulates that cancer-specific stress interferes with adaptation to cancer. Data from the randomized clinical trial of the biobehavioral intervention (BBI) showed reduced risk of recurrence and death from breast cancer for intervention participants (Andersen et al., 2008) and gains for all secondary outcomes (e.g., distress, social support; Andersen et al., 2007, 2004; Thornton, Andersen, \& Carson, 2008). Participants with clinically significant depressive symptoms $(n=45$ of 227$)$ who were randomized to BBI reported greater reductions in depressive symptoms compared with the Assessment Only arm (Thornton, Andersen, Schuler, \& Carson, 2009).

As we have discussed (Andersen, Golden-Kreutz, Emery, \& Theil, 2009), some components of BBI are the same as those in used in cognitive therapy for depression (Beck, Rush, Shaw, \& Emery, 1979). However, unlike BBI, CBT focuses efforts to reevaluate automatic thoughts, increase activity level (i.e., behavioral activation), and challenge core beliefs. Thus, the addition of CBT strategies not included in BBI would provide additional components needed for treating depression.

Our treatment development strategy was to offer a tailored, combined BBI/CBT intervention specifically designed for cancer patients with MDD. This Phase II trial had three aims. First, we 
tested the effects of the BBI/CBT intervention in reducing depressive symptoms and remission of depression. Second, we explored the contribution of individual differences previously found to be important in cancer (i.e., traumatic stress) or depression trials (i.e., history of prior episodes, presence of a comorbid anxiety disorder). Third, we tested for intervention effects on secondary outcomes relevant to cancer patients: QoL, pain, and fatigue.

\section{Method}

\section{Procedures and Participants}

Individuals with a current or prior cancer diagnosis and having current MDD as the primary diagnosis were eligible (including those taking psychotropic medication). Individuals were excluded if they (a) were diagnosed with a current Axis I disorder other than MDD requiring treatment other than that being offered or (b) had substance dependence within the past 6 months. Participants were accrued from July 2007 to December 2009 via two methods: mental health screening of postoperative gynecologic and breast cancer patients and selfreferral from the community. Those appearing eligible were sched- uled for a diagnostic assessment where informed consent was obtained and psychiatric status was determined, as approved by our Institutional Review Board. Patients were paid \$25-\$50 for assessments and received parking vouchers. See Figure 1 for study flow and Table 1 for a summary of descriptive characteristics.

\section{Intervention}

Procedures. Patients were offered 12-20 individual, 75-min sessions in an outpatient Department of Psychology clinic. Patients began with 12 weekly sessions, with assessments of remission at Sessions 10 and 12. Participants not meeting remission criteria after Session 12 received four additional weekly sessions. For these participants, symptoms were reevaluated at Session 16; nonremitters were offered an additional four weekly sessions. After 20 sessions, a final evaluation was conducted, and nonremitters were referred for treatment elsewhere. Figure 1 summarizes patients' treatment durations.

Therapy content, therapists, and intervention integrity. Components of both BBI and CBT were included in the treatment manual (see Table 2; Brothers, 2010). The manual provides guid-

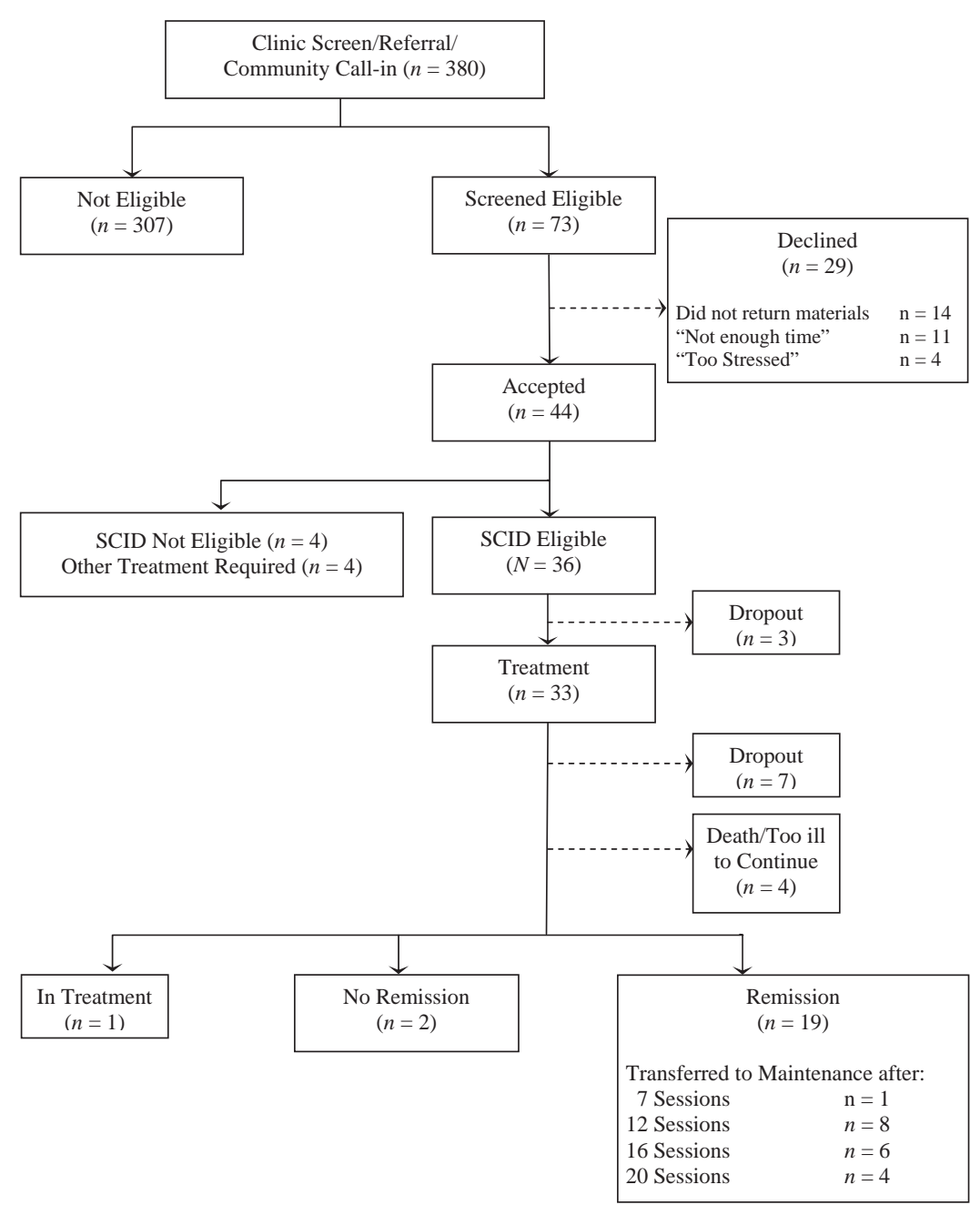

Figure 1. Study flow diagram. SCID = Structured Clinical Interview for DSM-IV. 
Table 1

Sociodemographic, Cancer Diagnosis/Treatment Information, and Psychopathology Characteristics of the Total Sample (N = 36) and by Three Subsamples of Newly Diagnosed/Treated, Disease-Free Survivors, and Those Diagnosed and in Treatment for Disease Progression or Recurrence

\begin{tabular}{|c|c|c|c|c|}
\hline Variable & $\begin{array}{l}\text { All patients }{ }^{\mathrm{a}} \\
\quad(N=36)\end{array}$ & $\begin{array}{l}\text { Patients diagnosed } \\
<12 \text { months }(n=13)\end{array}$ & $\begin{array}{c}\text { Disease-free } \\
\text { survivors }(n=12)\end{array}$ & $\begin{array}{c}\text { With disease } \\
\text { progression }(n=11)\end{array}$ \\
\hline \multicolumn{5}{|l|}{ Sociodemographic } \\
\hline Age, $M(S D)$ & $49(11)$ & $43(12)$ & $55(6)$ & $48(10)$ \\
\hline Education (in years), $M(S D)$ & $15(2)$ & $14(2)$ & $15(2)$ & $16(3)$ \\
\hline Household income (in thousand dollars), $M(S D)$ & $76(58)$ & $79(45)$ & $70(73)$ & $80(54)$ \\
\hline Ethnicity (\% Caucasian) & 89 & 85 & 100 & 82 \\
\hline Employment status (\% employed) & 39 & 46 & 33 & 36 \\
\hline Partner status ( $\%$ partnered) & 86 & 100 & 83 & 73 \\
\hline Gender (\% female) & 92 & 92 & 92 & 91 \\
\hline \multicolumn{5}{|l|}{ Cancer diagnosis and treatments } \\
\hline \multicolumn{5}{|l|}{ Site $(\%)$} \\
\hline Breast & 42 & 15 & 58 & 55 \\
\hline \multicolumn{5}{|l|}{ Gynecologic ( $19.4 \%$ ovarian, $8.4 \%$ endometrial, } \\
\hline Other $^{\mathrm{b}}$ & 28 & 31 & 42 & 9 \\
\hline \multicolumn{5}{|l|}{ Stage $(\%)$} \\
\hline I & 22 & 23 & 33 & 9 \\
\hline II & 22 & 15 & 33 & 18 \\
\hline III & 33 & 46 & 17 & 36 \\
\hline IV & 11 & 8 & 8 & 18 \\
\hline Unknown & 11 & 8 & 8 & 18 \\
\hline Years since initial diagnosis, $M(S D)$ & $3.81(4.55)$ & $.5(.3)$ & $6(5)$ & $6(5)$ \\
\hline Recurrence (\% yes) & 22 & 0 & 0 & 73 \\
\hline Second primary cancer ( $\%$ yes) & 11 & 8 & 17 & 9 \\
\hline Recent surgery $(\% \text { yes })^{\mathrm{c}}$ & 19 & 23 & 17 & 18 \\
\hline Current chemotherapy $(\% \text { yes })^{\mathrm{c}}$ & 44 & 62 & 8 & 64 \\
\hline Current radiation therapy $(\% \text { yes })^{\mathrm{c}}$ & 0 & 0 & 0 & 0 \\
\hline Current hormone therapy ( $\%$ yes) & 28 & 15 & 33 & 36 \\
\hline \multicolumn{5}{|l|}{ Psychopathology } \\
\hline \multicolumn{5}{|l|}{ Prior treatment for mental health concerns } \\
\hline (\% yes) & 42 & 31 & 25 & 73 \\
\hline Current psychotropic medication use (\% yes $)^{\mathrm{d}}$ & 58 & 54 & 50 & 73 \\
\hline Current comorbid anxiety disorder (\% yes) & 53 & 62 & 58 & 36 \\
\hline Prior depressive episodes (\% yes) & 50 & 46 & 75 & 27 \\
\hline
\end{tabular}

${ }^{a}$ Six patients had noncancer major medical treatment (e.g., gall bladder surgery) during the intervention. ${ }^{\mathrm{b}}$ Other sites include prostate, lung, melanoma, lymphoma, bowel, larynx, and renal. ${ }^{\mathrm{c}}$ At postassessment, one additional patient was recovering from a recent cancer surgery, two patients had begun radiation therapy, and 14 patients began or continued on chemotherapy. ${ }^{\mathrm{d}}$ Of the 21 patients on psychotropic medication when intervention sessions began, 15 patients continued with no change in dose, three patients ceased treatment, one patient decreased total dose, one patient increased total dose, and one patient decreased dosage of existing medication but added a new medication to increase overall "dose."

ance for tailoring strategies to patient characteristics. A companion intervention guidebook was provided to the patients. Two postdoctoral fellows and five predoctoral clinical psychology graduate students served as therapists. All had previous research experience and didactic education in cancer survivorship but had variable amounts of prior experience conducting therapy (ranging from 1 to 10 years). Weekly individual and group clinical supervision was provided. Using an experimenter-derived fidelity checklist of 54 essential BBI/CBT components, three tapes of Sessions 1-12 (36 tapes sampling across all clients and therapists) were rated by two individuals coding the presence/absence of components. Average kappa interrater reliability was .76 (93\% agreement), indicating substantially high agreement (Landis \& Koch, 1977). Then, Sessions 1-12 were rated for three patients, each having a different therapist. A fidelity score was created as a percentage by dividing number of components completed in the sessions divided by the 54 items on the fidelity checklist. Average fidelity was $85 \%$ (range $=$ 79\%-97\%).

\section{Measures}

Psychiatric diagnoses. Diagnostic status was assessed using the Structured Clinical Interview for DSM-IV (SCID; First, Spitzer, Gibbon, \& Williams, 2002). It has high reliability and validity. To assess current diagnostic reliability, recordings of 22 interviews were rated. Depression diagnoses were identical for 21 of 22 patients. Kappa interrater reliability was .83, indicating almost perfect agreement (Landis \& Koch, 1977). Concurrent anxiety disorders were also diagnosed, and kappa reliability was .79 , indicating good agreement.

\section{Depressive symptoms.}

Evaluator-rated. The 17-item Hamilton Rating Scale for Depression (HRSD; Williams, 1988) was administered at Sessions 7, 10, and 12, and if necessary, at Sessions 16 and 20. HRSD remission criteria were as follows: complete (score of 7 or less), partial (8-12), and no remission (13-54). This measure is reliable and valid (Williams, 1988). In this study, reliability was assessed 
Table 2

Summary of Therapy Session Content, Specified as a Component of the Biobehavioral Intervention (BBI) or Cognitive Behavior Therapy (CBT)

\begin{tabular}{|c|c|}
\hline $\operatorname{Session}(\mathrm{s})$ & Topic \\
\hline $1-12$ & Progressive muscle relaxation training (BBI) \\
\hline 1 & $\begin{array}{l}\text { Responding to the cancer crisis: Stress, } \\
\text { anxiety/depression, and coping (BBI) }\end{array}$ \\
\hline $2-3$ & $\begin{array}{l}\text { Coping: Seeking disease information and managing } \\
\text { treatment side effects (BBI) }\end{array}$ \\
\hline $2-4$ & $\begin{array}{l}\text { Behavioral activation: Rationale for mood } \\
\text { improvement, daily activity/symptom log, review } \\
\text { success and obstacles, scheduling activities (CBT) }\end{array}$ \\
\hline 4 & Communication with health care providers (BBI) \\
\hline $5-6$ & $\begin{array}{l}\text { Social support: Social network identification, emotional } \\
\text { versus tangible social support, negative versus } \\
\text { positive social support (BBI) }\end{array}$ \\
\hline $5-8$ & $\begin{array}{l}\text { Cognitive reappraisal: Rationale for mood } \\
\text { improvement, thought-records, generating alternative } \\
\text { thoughts }(\mathrm{CBT})\end{array}$ \\
\hline $7-8$ & $\begin{array}{l}\text { Communicating needs: Friends, coworkers, parents, } \\
\text { siblings, partners, children, and for patients without } \\
\text { partners (BBI) }\end{array}$ \\
\hline $8-9$ & $\begin{array}{l}\text { Problem solving: Defining the problem and generating } \\
\text { solutions, designing experiment/action plan (BBI) }\end{array}$ \\
\hline $9-10$ & $\begin{array}{l}\text { Core beliefs: Introduction and evaluation of core } \\
\text { beliefs (CBT) }\end{array}$ \\
\hline 10 & Exercise: Introduction to rhythmic walking (BBI) \\
\hline 11 & $\begin{array}{l}\text { Review of therapy components: Obstacles to } \\
\text { maintenance and stages of change as a process }(\mathrm{BBI})\end{array}$ \\
\hline 12 & Strategies for successful maintenance (CBT) \\
\hline
\end{tabular}

using ratings of recordings of 16 HRSD interviews. The intraclass correlation coefficient was .91 .

Self-reported. The 21-item Beck Depression InventorySecond Edition (BDI; Beck, Steer, \& Brown, 1996) was administered at all sessions. Sound psychometric properties have been documented, and criteria for clinical significance are scores ranging from 0 to 13 classified as minimal, 14 to 19 classified as mild, 20 to 28 classified as moderate, and 30 to 63 classified as severe (Beck et al., 1996). However, more conservative criteria were used to classify remission status: remitted $(\leq 9)$, partial (10-16), and no remission $(\geq 17)$.

\section{Individual differences.}

Cancer stress. The 22-item Impact of Events Scale (Horowitz, Wilner, \& Alvarez, 1979) was used to assess traumatic stress reactions to cancer diagnosis and treatment; the measure has shown adequate reliability and validity. Items are summed, with scores of 20 and higher indicating elevated cancer-specific distress.

Psychopathology severity. From the SCID, history of past depressive episodes $(0=$ none, $1=1$ or more $)$ and presence of a comorbid anxiety diagnosis $(0=$ none, $1=1$ or more $)$ were evaluated.

\section{General functioning.}

QoL. The Medical Outcomes Study Short Form-36 (SF-36; Ware et al., 1995) assessed health-related QoL; data show high validity and reliability. The Physical Component Summary and Mental Component Summary are scored and converted to $t$ scores $(M=50, S D=10)$.
Pain. The seven-item Brief Pain Questionnaire (Daut, Cleeland, \& Flanery, 1983) assesses patient's pain and its interference with functioning; data show adequate reliability and validity. Total scores range from 0 to 70 , with a higher score indicating greater pain interference.

Fatigue. The 7-item Total Disruption Index of the Fatigue Symptom Inventory (Hann et al., 1998) assesses fatigue and its interference with QoL; data show high reliability and validity. Total scores range from 0 to 70 , with a higher score indicating greater fatigue interference.

\section{Analytic Strategy}

Intent-to-treat analyses were conducted. Participant's last reported outcome value was used for effect size and generalized linear model analyses. Mixed-effects modeling (Raudenbush \& Bryk, 2002) estimated pretreatment depressive symptoms (intercept) and rate of change during treatment (linear and/or quadratic slope) using all data available from all 36 participants. The linear model was retained unless the fit of the quadratic model was significantly better $(\alpha=.05)$ than that of the linear model. Unconditional growth curves were estimated. Time was coded as number of weeks passed between each assessment. The maximum total number of BDI assessments that an individual could complete was 22 , and a median interval based on actual time between the assessments was calculated, resulting in a median of 26 weeks from pretreatment assessment to the 22nd assessment. To test the effects of individual differences, each individual difference variable and the Individual Difference $\times$ Time interaction were added to the models. Relevant covariates (partner status, employment status, receipt of recent surgery and/or chemotherapy, diagnosis of recurrence/second cancer, and psychotropic medication use) and their interaction with Time were also tested. Nonsignificant covariates $(p>.10)$ were removed from each model using a backward elimination. Pre- to posttreatment effect sizes and partial correlation coefficients ( $p r$; Rosenthal, 1994) were calculated. Generalized linear models tested the intervention effects on the secondary outcomes.

\section{Results}

\section{Descriptive}

Analyses comparing therapy noncompleters $(n=15)$ versus completers $(n=21)$ showed that the dropouts were more likely to be younger (mean age $=44$ vs. 53 years; $p=.007$ ), diagnosed with gynecologic cancer (60\% vs. $10 \% ; p=.003)$, currently receiving chemotherapy $(80 \%$ vs. $19 \% ; p<.001)$, and diagnosed with cancer recurrence ( $40 \%$ vs. $10 \% ; p=.03$ ). Considering all patients $(N=36)$, they received an average of 11 therapy sessions $(S D=7$; range $=0-20)$. See Table 3 for means, standard deviations, and internal consistency estimates for the outcome measures.

\section{Primary Outcomes and Individual Differences in Outcomes}

Outcomes from the mixed-effects models are presented in Table 4. For the BDI, the quadratic change model showed a better fit than 
Table 3

Descriptive Statistics for Outcome Measures at Pre- and Posttreatment Assessments Using Intent-to-Treat $(N=36)$

\begin{tabular}{|c|c|c|c|c|c|c|}
\hline \multirow[b]{2}{*}{ Measure } & \multicolumn{2}{|c|}{ Pretreatment } & \multicolumn{2}{|c|}{ Posttreatment } & \multirow[b]{2}{*}{ Effect size $(d)$} & \multirow[b]{2}{*}{ Internal consistency $(\alpha$} \\
\hline & $M$ & $S D$ & $M$ & $S D$ & & \\
\hline Beck Depression Inventory & 25.81 & 8.82 & \multicolumn{2}{|c|}{$2-48$} & 1.055 & .89 \\
\hline $\begin{array}{l}\text { Range } \\
\text { Hamilton Rating Scale for Depression } \\
\text { Range }\end{array}$ & $8-33$ & 5.41 & 13.17 & 8.68 & 0.898 & $.91^{\mathrm{a}}$ \\
\hline Brief Pain Questionnaire & 15.18 & 18.55 & 14.92 & 16.84 & 0.023 & .89 \\
\hline Fatigue Symptom Inventory & 35.15 & 15.42 & 28.82 & 18.52 & 0.477 & .94 \\
\hline SF-36 Physical Component Summary & 38.19 & 9.77 & 36.36 & 9.24 & 0.215 & .89 \\
\hline SF-36 Mental Component Summary & 34.97 & 9.32 & 44.04 & 11.44 & -0.750 & 77 \\
\hline
\end{tabular}

Note. $\quad$ SF-36 $=$ The Medical Outcomes Study Short Form-36.

${ }^{a}$ Intraclass coefficient is reported.

the linear model. Significant fixed effects for both linear $(p<$ $.001)$ and quadratic $(p=.002)$ changes in the BDI scores indicated a decline during the first 4 months and gains maintained through the next 2 months (see Figure 2A). For the observer rated HRSD, the linear change model showed a better fit than the quadratic. A significant fixed effect for linear slope $(p<.001)$ indicated a reduction in depressive symptoms, with scores declining across the 26 treatment weeks (see Figure 2B). To determine whether clinically significant change had been achieved, the index proposed by Jacobson, Roberts, Berns, and McGlinchey (1999) was used. Reliable change indices were 6.35 for BDI and 5.52 for HRSD. Thus, patients who showed a reduction of at least 7 points for BDI and 6 points for HRSD and posttreatment scores of 13 or less for BDI and 12 or less for HRSD would be considered to be clinically significant. Using all patients who provided at least one assessment score during treatment $(n=33$; see Figure 1), clinically significant changes were observed in $61 \%$ (20 of 33) of the patients using the BDI criterion and $69 \%$ (18 of 26) of patients using the HRSD criterion.

Patients with at least one comorbid anxiety disorder on both the BDI and HRSD and patients with higher cancer-specific stress on the BDI had significantly higher level of depressive symptoms at pretreatment $(p s<.01)$, after controlling for the relevant covariates. No significant pretreatment differences were noted for patients with higher cancer-specific stress on the HRSD or in patients with a prior depressive episode on either measure ( $p s>066)$. No differences in rate of improvement were noted for any patients $(p s>.336)$.

\section{Secondary Outcomes}

Interference due to fatigue-Total Disruption Index of the Fatigue Symptom Inventory, $F(1,32)=7.17, p=.012, d=$ 0.477-and mental health QoL-SF-36 Mental Component Summary, $F(1,32)=18.18, p<.001, d=-0.750$-were significantly improved. However, there were no improvements in interference due to pain-Brief Pain Questionnaire, $F(1$, $32)=0.17, p=.897, d=0.023$ - or physical health QoLSF-36 Physical Component Summary, $F(1,32)=1.52, p=$ $.227, d=0.215$.

\section{Discussion}

Depressive symptoms in cancer survivors receiving a combined BBI/CBT intervention declined significantly, as demonstrated using intent-to-treat analyses. Change was evident on both self-reported and interviewer-rated measures of depressive symptoms and accepted indicators of clinical change. Also, 19 of $21(90 \%)$ study completers achieved remission of the major depressive episode by treatment's end. These improvements are unlikely to have been due to changes in psychotropic medication, as dosages were increased for only two of 21 patients when in treatment. A single group, pre-post design was used. The use of repeated and multiple measurements of depression and measurements of therapy integrity reduced threats to internal validity (Eckert, 2000), but the results are nonexperimental and preliminary.

These data suggest that anxiety disorders and significant cancer stress may pose added challenges in designing efficacious treatments for cancer patients with MDD. Patients with comorbid anxiety and/or more cancer stress entered the study with more depressive symptoms, as had been found among psychiatric patients without cancer (Hirschfeld, 2001). Although no baseline differences were noted in patients with/ without a prior depressive episode, researchers should continue to examine the impact of past psychopathology, as this sample size may have been insufficient to detect effects from this individual difference.

Compared with baseline, patients reported improvements in fatigue and mental health QoL at the posttreatment assessment. Consistent with previous studies (e.g., Hersch, Juraskova, Price, \& Mullan, 2009), no changes were noted in pain or physical health QoL. The lack of change in physical health suggests that improvements in mental health functioning were more likely due to the intervention than improvements in disease state. In fact, half of the sample experienced disease progression or a major medical event during the trial.

We also consider the limitations of our sample, particularly in regards to feasibility of conducting future trials. Accrual occurred as expected, with $20 \%$ of those screened experiencing significant distress, similar to estimates of MDD (e.g., Raison $\&$ Miller, 2003). Despite our efforts, attrition was higher than we have experienced in previous trials $(4 \%$ in the Intervention 
Table 4

Mixed-Effects Modeling Results for Effects of Intervention and Individual Differences for the Beck Depression Inventory-Second Edition (BDI) and the Hamilton Rating Scale for Depression (HRSD)

\begin{tabular}{|c|c|c|c|c|}
\hline Variable & Estimate & $95 \% \mathrm{CI}$ & $t$ & $p r$ \\
\hline \multicolumn{5}{|c|}{ Intervention effect } \\
\hline \multicolumn{5}{|l|}{ BDI } \\
\hline Intercept & 25.384 & {$[22.446,28.322]$} & $17.402^{* * *}$ & .933 \\
\hline Linear slope & -1.244 & {$[-1.619,-0.869]$} & $-6.577^{* * *}$ & -.539 \\
\hline Quadratic & 0.026 & {$[0.010,0.042]$} & $3.189^{* * *}$ & .285 \\
\hline \multicolumn{5}{|l|}{ HRSD } \\
\hline Intercept & 19.710 & {$[18.049,21.372]$} & $23.955^{* *}$ & .966 \\
\hline Linear slope & -0.619 & {$[-0.811,-0.426]$} & $-6.645^{* *}$ & -.811 \\
\hline \multicolumn{5}{|c|}{ Prior depressive episodes on intervention effect } \\
\hline \multicolumn{5}{|c|}{ 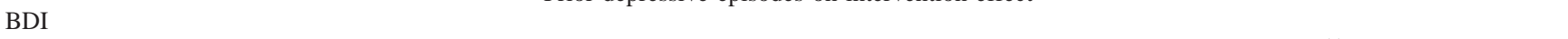 } \\
\hline Intercept & 24.106 & {$[19.317,28.895]$} & $10.151^{* *}$ & .840 \\
\hline Prior depressive episodes & 5.053 & {$[-0.359,10.465]$} & -1.889 & .289 \\
\hline Linear slope & -0.864 & {$[-1.418,-0.309]$} & $-3.137^{* *}$ & -.420 \\
\hline Quadratic & 0.027 & {$[0.011,0.043]$} & $3.342^{* *}$ & .298 \\
\hline Prior depressive episodes $\times$ Linear slope & -0.160 & {$[-0.620,0.300]$} & -0.715 & -.351 \\
\hline \multicolumn{5}{|l|}{ HRSD } \\
\hline Intercept & 18.703 & {$[13.880,23.526]$} & $7.772^{* * *}$ & .723 \\
\hline Prior depressive episodes & 1.338 & {$[-2.007,4.683]$} & 0.802 & .108 \\
\hline Linear slope & -0.936 & {$[-1.407,-0.465]$} & $-4.076^{* *}$ & -.610 \\
\hline Prior depressive episodes $\times$ Linear slope & -0.065 & {$[-0.398,0.268]$} & -0.397 & -.066 \\
\hline \multicolumn{5}{|c|}{ Comorbid anxiety disorder on intervention effect } \\
\hline \multicolumn{5}{|c|}{ e } \\
\hline Intercept & 16.541 & {$[8.980,24.103]$} & $4.434^{* * *}$ & .592 \\
\hline Comorbid anxiety disorder & 7.156 & {$[2.081,12.231]$} & $2.849^{* * *}$ & .411 \\
\hline Linear slope & -1.135 & {$[-1.571,-0.699]$} & $-5.195^{* *}$ & -.542 \\
\hline Quadratic & 0.027 & {$[0.011,0.043]$} & $3.311^{* *}$ & .296 \\
\hline Comorbid anxiety disorder $\times$ Linear slope & -0.197 & {$[-0.640,0.247]$} & -0.926 & -.203 \\
\hline \multicolumn{5}{|l|}{ HRSD } \\
\hline Intercept & 16.393 & {$[11.794,20.993]$} & $7.130^{* * *}$ & 677 \\
\hline Comorbid anxiety disorder & 4.474 & {$[1.590,7.358]$} & $3.105^{* *}$ & .378 \\
\hline Linear slope & -0.893 & {$[-1.369,-0.416]$} & $-3.816^{* * *}$ & -.559 \\
\hline Comorbid anxiety disorder $\times$ Linear slope & -0.072 & {$[-0.366,0.222]$} & -0.498 & -.086 \\
\hline \multicolumn{5}{|c|}{ Cancer-specific stress (Impact of Events Scale) on intervention effect } \\
\hline \multicolumn{5}{|c|}{ 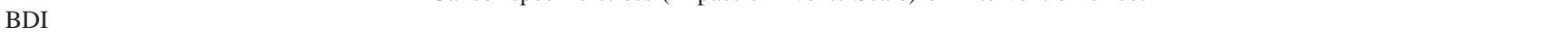 } \\
\hline Intercept & 8.703 & {$[0.072,17.334]$} & $2.049^{*}$ & .332 \\
\hline Cancer-specific stress & 0.240 & {$[0.069,0.411]$} & $2.843^{* *}$ & .428 \\
\hline Linear slope & -0.562 & {$[-1.272,0.149]$} & -1.596 & -.239 \\
\hline Quadratic & 0.022 & {$[0.007,0.038]$} & $2.806^{* *}$ & .252 \\
\hline Cancer-specific stress $\times$ Linear slope & -0.008 & {$[-0.025,0.009]$} & -0.980 & -.187 \\
\hline \multicolumn{5}{|l|}{ HRSD } \\
\hline Intercept & 11.288 & {$[5.999,16.577]$} & $4.286^{* * *}$ & .518 \\
\hline Cancer-specific stress & 0.045 & {$[-0.063,0.153]$} & 0.841 & .118 \\
\hline Linear slope & -0.388 & {$[-0.853,0.077]$} & -1.699 & -.284 \\
\hline Cancer-specific stress $\times$ Linear slope & -0.004 & {$[-0.015,0.008]$} & -0.641 & -.109 \\
\hline
\end{tabular}

${ }^{*} p<.05 . \quad * * p<.01$.

arm in Andersen et al., 2004). Whereas symptoms of low motivation may impact attrition in depression trials, these patients also had physical debilitation or time limitations for those receiving cancer treatment concurrently. For example, three patients did not begin treatment; all three patients were in chemotherapy and stated that there was "too much stress right now" to start therapy. To address this issue, coordinating care to minimize patient travel time and burden is critical, and holding therapy sessions in a maximally convenient location might be considered. In our view, the severity and complexity of the clinical presentation suggest that individual treatment is necessary (and standard for MDD) but is nonetheless atypical among psychological interventions in cancer. Another consideration is that minority and underserved patients with fewer resources than our predominantly Caucasian sample with above-average education/income may experience even higher levels of depressive symptoms. Lastly, the accrued sample was more health impaired than typical in cancer psychosocial trials (Andersen, 1992, 2002) and in our previous trial (Andersen et al., 2004). One third of patients had disease progression. Understandably, these circumstances derail session agendas, and some of the therapy content seemed less suitable for them (e.g., behavioral activation). Thus, at this time we are testing another treatment rather than $\mathrm{BBI} / \mathrm{CBT}$ with those with recurrence. However, the 

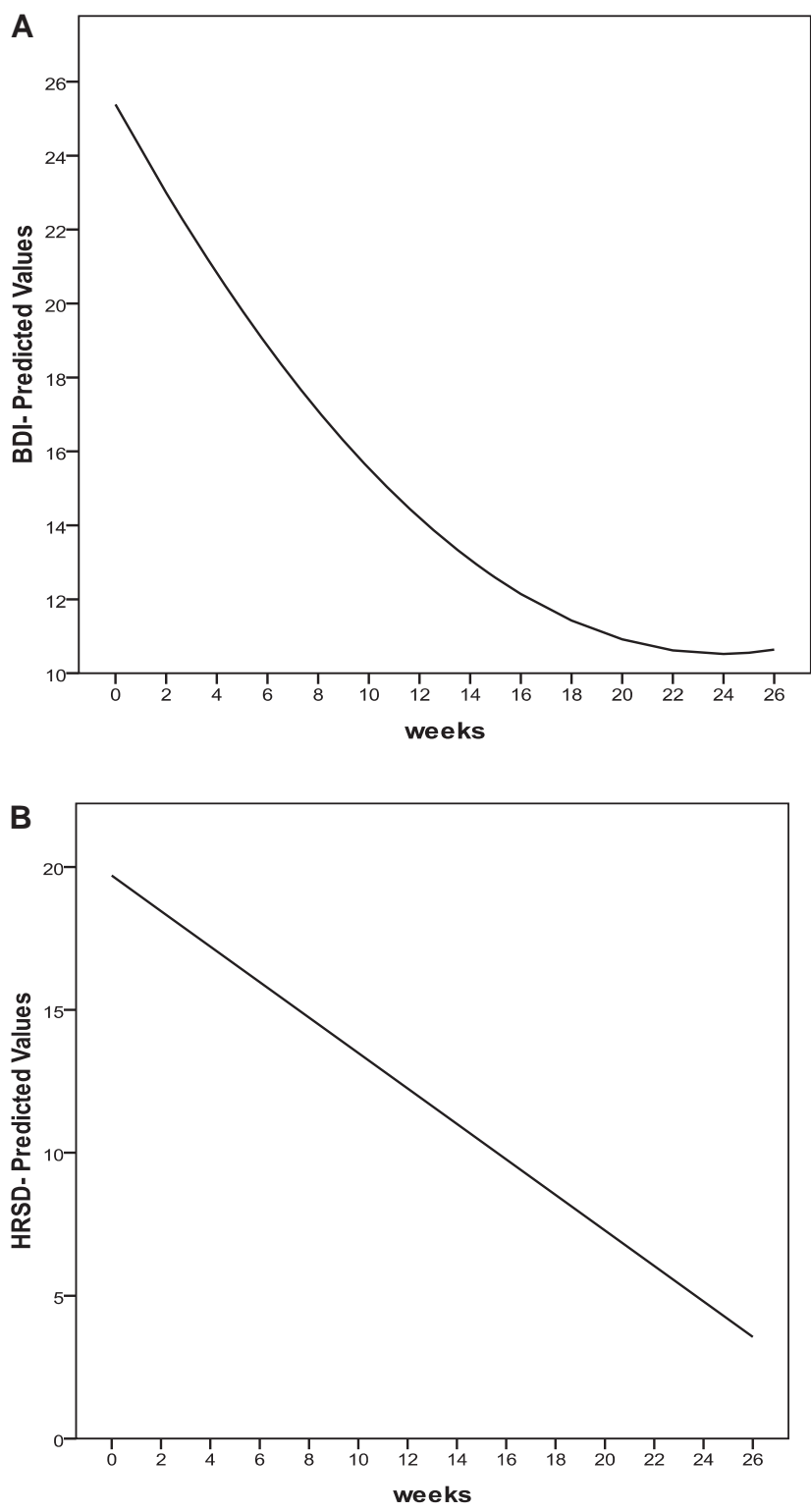

Figure 2. Predicted scores for (A) the Beck Depression InventorySecond Edition (BDI) and (B) the Hamilton Rating Scale for Depression (HRSD) using mixed-effects modeling $(N=36)$. The time period was the 26 weeks of the biobehavioral/cognitive behavior therapy intervention.

aims of this Phase II trial to evaluate the effectiveness of the $\mathrm{BBI} / \mathrm{CBT}$ intervention were achieved, suggesting that comparison of $\mathrm{BBI} / \mathrm{CBT}$ with standard treatments is warranted.

\section{References}

Andersen, B. L. (1992). Psychological interventions for cancer patients to enhance the quality of life. Journal of Consulting and Clinical Psychology, 60, 552-568. doi:10.1037/0022-006X.60.4.552

Andersen, B. L. (2002). Biobehavioral outcomes following psychological interventions for cancer patients. Journal of Consulting and Clinical Psychology, 70, 590-610. doi:10.1037/0022-006X.70.3.590

Andersen, B. L., Farrar, W. B., Golden-Kreutz, D., Emery, C. F., Glaser,
R., Crespin, T., \& Carson, W. E., III. (2007). Distress reduction from a psychological intervention contributes to improved health for cancer patients. Brain, Behavior, and Immunity, 21, 953-961. doi:10.1016/ j.bbi.2007.03.005

Andersen, B. L., Farrar, W. B., Golden-Kreutz, D. M., Glaser, R., Emery, C. F., Crespin, T., . . Carson, W. E., III. (2004). Psychological, behavioral, and immune changes following a psychological intervention: A clinical trial. Journal of Clinical Oncology, 22, 3570-3580. doi: 10.1200/JCO.2004.06.030

Andersen, B. L., Golden-Kreutz, D. M., Emery, C. F., \& Theil, D. L. (2009). Biobehavioral intervention for cancer stress: Conceptualization, components, and intervention strategies. Cognitive and Behavioral Practice, 16, 253-265. doi:10.1016/j.cbpra.2008.11.002

Andersen, B. L., Kiecolt-Glaser, J. K., \& Glaser, R. (1994). A biobehavioral model of cancer stress and disease course. American Psychologist, 49, 389-404. doi:10.1037/0003-066X.49.5.389

Andersen, B. L., Yang, H.-C., Farrar, W. B., Golden-Kreutz, D. M., Emery, C. F., Thornton, L. M., .. . Carson, W. E., III. (2008). Psychological intervention improves survival for breast cancer patients: A randomized clinical trial. Cancer, 113, 3450-3458. doi:10.1002/cncr.23969

Beck, A. T., Rush, A. J., Shaw, B. F., \& Emery, G. (1979). Cognitive therapy of depression. New York, NY: Guilford Press.

Beck, A. T., Steer, R. A., \& Brown, G. K. (1996). Manual for Beck Depression Inventory - II. San Antonio, TX: The Psychological Corporation.

Brothers, B. M. (2010). An examination of treatment for depression in female cancer patients. Dissertation Abstracts International, 70, 10-B. (UMI No. 3375726)

Burgess, C., Cornelius, V., Love, S., Graham, J., Richards, M., \& Ramirez, A. (2005). Depression and anxiety in women with early breast cancer: Five year observational cohort study. British Medical Journal, 330, 702-705. doi:10.1136/bmj.38343.670868.D3

Daut, R. L., Cleeland, C. S., \& Flanery, R. C. (1983). Development of the Wisconsin Brief Pain Questionnaire to assess pain in cancer and other diseases. Pain, 17, 197-210. doi:10.1016/0304-3959(83)90143-4

Eckert, W. A. (2000). Situational enhancement of design validity: The case of training evaluation at the World Bank Institute. American Journal of Evaluation, 21, 185-193.

First, M. B., Spitzer, R. L., Gibbon, M., \& Williams, J. B. W. (2002). Structured Clinical Interview for DSM-IV Axis I Disorders, Research Version, Non-Patient Edition (SCID-I/NP). New York, NY: Biometrics Research, New York State Psychiatric Institute.

Golden-Kreutz, D. M., \& Andersen, B. L. (2004). Depressive symptoms after breast cancer surgery: Relationships with global, cancer-related, and life event stress. Psycho-Oncology, 13, 211-220. doi:10.1002/pon.736

Hann, D. M., Jacobsen, P. B., Azzarello, L. M., Martin, S. C., Curran, S. L., Fields, K. K., ... Lyman, G. (1998). Measurement of fatigue in cancer patients: Development and validation of the Fatigue Symptom Inventory. Quality of Life Research, 7, 301-310. doi:10.1023/A:1008842517972

Hersch, J., Juraskova, I., Price, M., \& Mullan, B. (2009). Psychosocial interventions and quality of life in gynaecological cancer patients: A systematic review. Psycho-Oncology, 18, 795-810. doi:10.1002/pon.1443

Hirschfeld, R. M. (2001). The comorbidity of major depression and anxiety disorders: Recognition and management in primary care. Primary Care Companion to the Journal of Clinical Psychiatry, 3, 244-254.

Hopko, D. R., Bell, J. L., Armento, M., Robertson, S., Mullane, C., Wolf, N., \& Lejuez, C. W. (2008). Cognitive-behavior therapy for depressed cancer patients in a medical care setting. Behavior Therapy, 39, 126136. doi:10.1016/j.beth.2007.05.007

Horowitz, M., Wilner, N., \& Alvarez, W. (1979). Impact of Event Scale: A measure of subjective stress. Psychosomatic Medicine, 41, 209-218.

Jacobson, N. S., Roberts, L. J., Berns, S. B., \& McGlinchey, J. B. (1999). Methods for defining and determining the clinical significance of treatment effects: Description, application, and alternatives. Journal of Consulting and Clinical Psychology, 67, 300-307. doi:10.1037/0022-006X.67.3.300 
Landis, J. R., \& Koch, G. G. (1977). The measurement of observer agreement for categorical data. Biometrics, 33, 159-174. doi:10.2307/2529310

McDonald, M. V., Passik, S. D., Dugan, W., Rosenfeld, B., Theobald, D. E., \& Edgerton, S. (1999). Nurses' recognition of depression in their patients with cancer. Oncology Nursing Forum, 26, 593-599.

Palmer, S. C., Kagee, A., Coyne, J. C., \& DeMichele, A. (2004). Experience of trauma, distress, and posttraumatic stress disorder among breast cancer patients. Psychosomatic Medicine, 66, 258-264. doi:10.1097/ 01.psy.0000116755.71033.10

Raison, C. L., \& Miller, A. H. (2003). Depression in cancer: New developments regarding diagnosis and treatment. Biological Psychiatry, 54, 283-294. doi:10.1016/S0006-3223(03)00413-X

Raudenbush, S. W., \& Bryk, A. S. (2002). Hierarchical linear models. Newbury Park, CA: Sage.

Rosenthal, R. (1994). Parametric measures of effect size. In H. Cooper, L. V. Hedges (Eds.), The handbook of research synthesis (pp. 231-244). New York, NY: Russell Sage.

Savard, J., Simard, S., Giguere, I., Ivers, H., Morin, C. M., Maunsell, E., . . Marceau, D. (2006). Randomized clinical trial on cognitive therapy for depression in women with metastatic breast cancer: Psychological and immunological effects. Palliative and Supportive Care, 4, 219-237. doi:10.1017/S1478951506060305

Sheard, T., \& Maguire, P. (1999). The effect of psychological interventions on anxiety and depression in cancer patients: Results of two meta-analyses. British Journal of Cancer, 80, 1770-1780. doi:10.1038/sj.bjc.6690596

Smith, E. M., Gomm, S. A., \& Dickens, C. M. (2003). Assessing the independent contribution to quality of life from anxiety and depression in patients with advanced cancer. Palliative Medicine, 17, 509-513. doi:10.1191/0269216303pm781oa

Thornton, L. M., Andersen, B. L., \& Carson, W. E., III. (2008). Immune, endocrine, and behavioral precursors to breast cancer recurrence: A case-control analysis. Cancer, Immunology, and Immunotherapy, 57, 1471-1481. doi:10.1007/s00262-008-0485-6

Thornton, L. M., Andersen, B. L., Schuler, T. A., \& Carson, W. E., III. (2009). A psychological intervention reduces inflammatory markers by alleviating depressive symptoms: Secondary analysis of a randomized controlled trial. Psychosomatic Medicine, 71, 715-724. doi:10.1097/ PSY.0b013e3181b0545c

Ware, J. E., Kosinski, M., Bayliss, M. S., McHorney, C. A., Rogers, W. H., \& Raczek, A. (1995). Comparison of methods for the scoring and statistical analysis of SF-36 health profile and summary measures: Summary of results from the medical outcomes study. Medical Care, 33, AS264-AS279.

Weber, B. A., Roberts, B. L., Resnick, M., Deimling, G., Zauszniewski, J. A., Musil, C., \& Yarandi, H. N. (2004). The effect of dyadic intervention on self-efficacy, social support, and depression for men with prostate cancer. Psycho-Oncology, 13, 47-60. doi:10.1002/pon.718

Williams, J. B. (1988). A structured interview guide for the Hamilton Depression Rating Scale. Archives of General Psychiatry, 45, 742-747.

Received October 6, 2010 Revision received November 29, 2010 Accepted December 6, 2010

\section{ORDER FORM}

\section{Start my 2011 subscription to the Journal of Consulting and Clinical Psychology ISSN: 0022-006X}

\section{$\$ 126.00$ APA MEMBER/AFFILIATE \\ $\$ 280.00$ INDIVIDUAL NONMEMBER \\ $\$ 907.00$ INSTITUTION \\ In DC and MD add $6 \%$ sales tax \\ TOTAL AMOUNT DUE}

$\$$

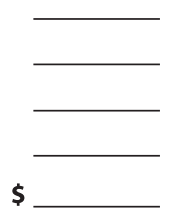

Subscription orders must be prepaid. Subscriptions are on a calendar year basis only. Allow 4-6 weeks for delivery of the first issue. Call for international subscription rates.

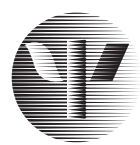

AMERICAN PSYCHOLOGICAL ASSOCIATION

\section{SEND THIS ORDER FORM TO}

American Psychological Association

Subscriptions

750 First Street, NE

Washington, DC 20002-4242

Call 800-374-2721 or 202-336-5600

Fax 202-336-5568 :TDD/TTY 202-336-6123

For subscription information,

e-mail: subscriptions@apa.org $\square$ Check enclosed (make payable to APA)

Charge my: $\square$ Visa $\square$ MasterCard $\square$ American Express

Cardholder Name

Card No. Exp. Date

Signature (Required for Charge)

\section{Billing Address}

Street

City _ State _ Zip _ _

Daytime Phone

E-mail

\section{Mail To}

Name

Address

\begin{tabular}{ll}
\hline City & State $\_$Zip \\
APA Member \# &
\end{tabular}

